\title{
Regression Analysis for Analyzing Life Style Risk Factor of Diabetes in Pakistan \\ Zahid Iqbal, Qaiser
}

Department of Statistics, Allama Iqbal Open University, Islamabad, Pakistan

\begin{abstract}
Article Info

Volume 8, Issue 1

Page Number: 94-103

Publication Issue :

January-February-2021

Article History

Accepted : 01 Jan 2021

Diabetes is a worldwide metabolic disease. In Pakistan prevalence of diabetes is increasing day by day. This research aims to analyze the risk factors associated with the patient in the Malakand division, KPK Pakistan. The data is collected from four districts of Malakand division District Headquarter Hospital for the period year 2018. The insignificant risk factors are eliminated using the backward Elimination method for the Binary logistic Regression model and for a best-fitted model, the AIC technique is used, while the logistic Coefficient is tested with help of Wald statistic and Hosmer-Lemeshow is performed for the Goodness of fit test. The positive and negative association among risk factors with diabetes is checked with the help of a Chi-square and odds ratio. Based on P-value at $5 \%$ level of significance the risk factors Age, cholesterol level, Hypertension, Family History, and Obesity are sensitive risk factors to develop diabetes. The AIC also show same best-fitted model while according to Hosmer- Lemeshow 0.844 indicating a better fit and these risk factors are associated with diabetes for the combine data of Malakand division. In each districts, the significant risk factors that affect to develop diabetes are Age, Cholesterol level and Obesity while according to AIC the best-fitted model is that in which the risk factors Gender and Occupation Status are involved the risk factor obesity show low level of precision based on 95\% Confidence Interval and Chisquare statistic shows these factors are associated with diabetes.
\end{abstract}

Published : 24 Jan 2021
Keywords : Risk factors, diabetes, logistic regression, age, AIC.

\section{INTRODUCTION}

Diabetes Mellitus or Diabetes is a condition in which a body fails to properly process or convert food in to glucose or sugar to use as energy. The pancreas make insulin to maintain glucose in the cells of a body. There is no cure for diabetes, in diabetes the body is unable to make sufficient amount of insulin or it cannot use its own insulin which cause high/low sugar level in body which people also called as sugar. The recent study shows that diabetes cases increases world widely (IDF, 2011). With changing life style, rapid economic growth the diabetes become a major issue of public health in many countries (WHO, 2013, 2011). The symptoms of diabetic include extreme hunger, excessive thirst, frequent urination, 
unexplained weight loss, sudden vision changes, numbness in hands of feet, feeling very tired much of the time, very dry skin, sores that are slow to heal, more infections than usual etc. There are two types of diabetes i.e. Type $1 \&$ Type 2 . The Type-1 diabetes also known as insulin dependent diabetes mellitus (IDDM). In this type of diabetes pancreas is unable to provide required level of insulin for the body. The ratio of this type diabetes diagnosed case are from $5 \%$ to $10 \%$. Defined Risk factors for this type of diabetes is less than that of type-2 mainly environmental factors, family history, Age, viral infection etc. are involved in growth of type 1 diabetes. While the Type 2 diabetes also known as Non-insulin dependent diabetes mellitus (NIDDM). In Type-2 of diabetes, the level of sugar in blood become too high. The ratio of this type diabetes diagnosed case are from $90 \%$ to 95\%. Defined Risk factors for this type of diabetes are older Age, obesity, family history, impaired glucose tolerance, physical inactivity, hyper tension, prior history of gestational diabetes etc. Worldwide diabetes cases are 463 million in 2019 and estimated to be touch 578 million figures by 2030. The prevalence of diabetes is high in urban areas as compared to rural area due to life style, physical inactivity and extended workloads etc. In worldwide china has the most diabetic cases than any other country. The reported diabetic cases in china as on 2019 are 108.6 to 145 million. After china, India and United States, Pakistan has maximum diabetic cases in the world which is a matter of great concern. In fall 2019 there were about 30.4 million reported diabetic cases in the Age between 19 to 80, which is approximately $13.81 \%$ of the national population (Alberti et al., 2009). Pakistan rank are 4th in diabetic patient in the whole world (Aamir et al., 2019). About $17.1 \%$ adult population are affected with diabetics. The provincial pattern of prevalence is as follows: Punjab; 30.2\%, Khyber Pakhtunkhwa; 13.2\%, Baluchistan; 29.5\% and Sindh; 32.3\%. These figures equate to approximately 27.4 million people aged 20 and above, based on the 207.77 million total population (Saeedi et al., 2019). Ahmad and Pervaiz (2006) explore the effect of different risk factors on diabetes was estimated in various hospital- based study both with descriptive and systematic components. Sample of 580 persons aged 20 years and above (153 men, 427 women) entering the diabetic enter as outdoor patents during the months (March 2002 - August 2002) were taken. Urine and blood glucose test were conducted and the diabetes was diagnosed according to W.H.O criteria. Risk factors i.e. Heights, Weights, BMI and hypertension (blood pressure) of the studied population were collected. The Chi-square test was used to measure the association among the different risk factors of independent variables and logistic regression model was applied to check the main significant risk factors and for the prediction model. Ismail and Anil (2014) in urban and industrial area the life style dieses, coronary artery dieses (CAD), one of the life style dieses that affect at a younger age can have different results for an individual the family and society prevention of these dieses. The researchers by using a standard questionnaire, for collection off data from the CAD patent and then analyzing the association among the risk factors of CAD. One of the lifestyle diabetes (diabetes, physical fitness at an adult can have divesting results for an observer). The family and environment, prevention of these diabetes disease can be done by studying the risk factors for analyzing and interpreting them using the binary logistic model in this model the dependent cardiovascular risk scores the author wanted to assess whether non parametric smoothing of the cardiovascular risk scores can be used as a batter statistical technique as compared to the former technique. In the last twenty (20) years type- 2 diabetes rapidly increases the risk factors of coronary heart dieses (CHD) more in women as compared to men. By different study of the risk factors of diabetes related CHD risk in men and women is widely increasing. The absolute risk CHD 
in women suffering from diabetic is partially understood, but certain explanations can be offered. First, inverse changes by type- 2 diabetes in cardiovascular risk factors, such as HDL cholesterol, triglycerides, LDL particle size, and hyper tension (BP), was found to be more severe factor for women as compared to men (6-8). Cardiovascular risk factors for CHD in diabetics, is more affecting risk factor for women due to take different kind of tensions. So cardiovascular factors affect women's less in protective mechanisms than men and there by lead to enhanced atheromasias or thrombogenesis.

\section{OBJECTIVES}

The following are the main objective this study

To determine regression analysis among the risk factors of diabetes in the Malakand Division. And to know the reasons of diabetes in the targeted Population. To determine the significant difference in the risk factors of various districts of Malakand division.

\section{MATERIALS AND METHODS}

Dataset We have taken sample of 1021 of diabetic patients both male and female in districts of Malakand division. The data consist of four District Headquarter hospitals(DHQ) (Bathkhela, Mingora, Bunner and Timergrah ). The diabetic patients are 507 and non-diabetic patient are 514. First, we have taken data as a whole of the four districts of Malakand Division and studied which factor is more significant for diabetic patient. Secondly, risk factors have analyzed by each district hospital. For significance, the Binary Logistic Regression Model has been used because in this study the depended variables are categorical response variables i-e diabetic or non diabetic and independent variables are the risk factors i-e Age, Gender, Smoking, Hypertension, Family
History of diabetes, Cholesterol Level, Occupation Status, life style Exercise and Obesity. Ismail and Anil (2014) Over the past period, most the researcher used the Logistic Regression Model because it is very important model for such type of data and is popularly used a tool for statistical analysis Logistic Regression Model is used to find the most parsimonious set of predictors that are effective in predicting the dependent variable.

\section{STUDY DESIGN}

Regression analysis is statistical technique for investigating and modeling the relationship between variables. The term regression was introduced by "Francis Galton" in his paper is "family likeness in nature" which was published in 1886 in London. Regression means to regress (to go back towards the average). Regression investigate the dependence of one variable upon other one or more variables. In regression the one variable is called depended variable while the other variables are independent variables.

\section{STATISTICAL ANALYSIS}

The logistic regression model is also known as logistic regression or logistic model, is a mathematical model used in statistics to estimate (guess) the probability of an event occurring have been given some previous data. Logistic regression work with binary data where either the even happens (1) or the event does not happen (0), pass or fail, bad or good etc. logistic regression is a statistical technique used to predict probability of binary response. Based on one more independent variable it means that a given certain factors, logistic regression is used to predict an outcome which has two values such as yes to no, diabetic or non diabetic. Mathematical Form of Model $\log (\mathrm{p} / \mathrm{q})=\alpha+\beta \mathrm{x}(1)$ For Example $\mathrm{P}(\mathrm{Y}=1)=\mathrm{p}$ for diabetic patient, where $\mathrm{p}$ is $\mathrm{p}=\mathrm{e}(\alpha+\beta \mathrm{xt}) /[1+\mathrm{e}$ 
$(\alpha+\beta x t)$ ] (2) Where $\mathrm{p}$ denote the probability of diabetic patient. In Simple Binary Logistic regression model is concerned with one independent variable, but if there are more than one independent variables or several variable appear in the model then we use Multiple Logistic Regression Model. Mathematical Form of Model $\log (\mathrm{p} / \mathrm{q})=\alpha+\beta 1 \mathrm{x} 1+\beta 2 \mathrm{x} 2$ $+\ldots . . . . \beta \mathrm{kxk}$ (3) The parameters in the model are $\alpha$ and $\beta \mathrm{i}$, where the $\alpha$ is the intercept (constant) of the model while $\beta \mathrm{i}$ are the slope parameters (regression coefficient) with $\mathrm{i}=1,2,3, \ldots \mathrm{k}$ An Odds Ratio is a measure $\mathrm{pf}$ association between an revealing and an outcome it represent the odds that an outcome will occur given a particular reveal. It is also the measure of the strength of association with an exposure and an outcome. Three condition are used to estimate the strength of various risk factors. - If OR $>1$ it represent that the association between the exposure and outcome will be greater. - If $\mathrm{OR}=1$ means that there is no association between the exposure and outcome. - If $\mathrm{OR}<1$ shows that there will be lower odds between the reveal and outcome. In logistic regression the Odds Ratio shows the constant effect of a predictor $\mathrm{X}$, on the likelihood that one outcome will occur in logistic regression model. The association is positive if $\mathrm{OR}>1$ and it means that higher number for the predictor. The association is negative means low number for predictor if $\mathrm{OR}<1$. The Chi-Square test evaluates the magnitude of discrepancy between observed and expected frequencies. It is used to determine whether there is a statistically significant difference between observed frequencies in one or more categories of a contingency table, also it measure. The significance of association between two categorical variables. The Null and an alternative hypothesis is stated as $\cdot \mathrm{HO}$ : There is no relationship between the categorical variables. - H1 : There is relationship between the categorical variables. To test the significance of regression Co-efficient $\mathrm{B}^{\wedge}$ individually. The Wald test is a statistical test of estimated parameters in a model.
The Wald Statistic can be calculated by formula; Wi = $\mathrm{Bi}^{\wedge} 2$ / $\left[\mathrm{SE}\left(\mathrm{Bi}^{\wedge}\right)\right] 2$ (4) The $\mathrm{Bi}^{\wedge}$ denotes the estimated regression Co-efficient and $\mathrm{SE}\left(\mathrm{Bi}^{\wedge}\right)$ represents Standard Error of regression Co-efficient. 4. RESULTS The data of risk factors of diabetes for both male and female at Malakand division will be analyzed in this chapter. The considered relative risk factors of diabetes (Type-1 and Type-2) for this study are Age,Gender, Occupation Status, Hypertension, Family History, cholesterol level, Smoking, Exercise, and Obesity. Also the response variable has two nominal categories Diabetic patients or Non Diabetic patients for Diabetic patien, $\mathrm{y}=1$ and for Non Diabetic patient $=0$. From various hospital (DHQ Batkhela, DHQ Swat, DHQ Bunner and DHQ Timergara) of Khyber Pakhtun Khwa, 1021 patients of diabetes has been recorded for this analysis. The binary logistic regression model is used to predict the significant effect of risk factors first for whole data of Malakand Division and then for each District of Malakand Division.

\section{RESULTS}

To select the best fitted model from a set of models, Scholar used AIC. The stepwise fitted models and some important results will be explained with the help of Backward Elimination Method. The number of patients recorded from various districts in Malakand Division are given the following table.

Table 1 : Total Diabetic Patients

\begin{tabular}{|c|c|c|}
\hline $\begin{array}{c}\text { Diabetic } \\
\text { Patients }\end{array}$ & $\begin{array}{c}\text { Non Diabetic } \\
\text { Patients }\end{array}$ & Total \\
\hline 507 & 514 & 1021 \\
\hline
\end{tabular}

The following table 2 show descriptive statistics for the age of the respondents for 1021 patients of diabetes. 
Table 2 : Descriptive Statistics of Age in Malakand Division

\begin{tabular}{|l|c|c|c|c|l|l|c|}
\hline $\begin{array}{l}\text { Fac } \\
\text { tors }\end{array}$ & $\begin{array}{c}\text { Mini } \\
\text { mum }\end{array}$ & $\begin{array}{l}\text { Maxi } \\
\text { mum }\end{array}$ & $\begin{array}{l}\text { Me } \\
\text { an }\end{array}$ & $\begin{array}{l}\text { Me } \\
\text { dian }\end{array}$ & $\begin{array}{l}\text { M } \\
\text { od } \\
\text { e }\end{array}$ & $\begin{array}{l}\text { Skew } \\
\text { ness }\end{array}$ & $\begin{array}{l}\text { Kurt } \\
\text { osis }\end{array}$ \\
\hline Age & 9 & 95 & $\begin{array}{c}50 . \\
113\end{array}$ & 50 & 60 & 0.07 & - \\
\hline
\end{tabular}

From above table 2, the minimum age of the respondent is 9 years, maximum age is 95 , the mean, median and mode are 50.113, 50 and 60 respectively, while the skewness is 0.07 means that age is approximately symmetric and kurtosis is -0.33 means that age represent platykurtic curve. From, the descriptive statistics it is concluded that the mean, median and mode are not coincide with each other, which represent that the data is not normally distributed. Also the Skweness shows the data is pulled to the slightly right side, while Kurtosis denotes Platykurtic curve with respect to normal Curve, thus the Binary logistic regression model is proposed because of its assumption. The table 3 shows the dependent and independent variables of the model and equation represents the general form of the model.

\section{$\log (\mathrm{p} / \mathrm{q})=\beta_{0}+\beta_{1}$ Age $+\beta_{2}$ Gender $+\beta_{3} \mathrm{OS}+\beta_{4} \mathrm{CRL}+$ $\beta_{5} \mathrm{H}+\beta_{6} \mathrm{FH}+\beta_{7} \mathrm{~S}+\beta_{8} \mathrm{E}+\beta_{9} \mathrm{O}+v_{\mathrm{i}}$}

The binary logistic regression model is fitted to the relative risk factors Age, Gender, Occupation Status, Hypertension, Family History, Cholesterol level, Smoking, Exercise and Obesity while the dependent variable is diabetic risk score. The binary logistic regression model is fitted with the help of backward elimination method which provide the significant and insignificant risk factors result in four steps. In first step, the significant risk factors for diabetes are Age, Hypertension, Family history, Exercise and obesity while the risk factors which are not effected for whole data of diabetes are Gender, Occupation states and smoking because their $\mathrm{p}$-values are greater than 0.05 while is insignificant. Now in step- 2 the binary logistic regression model is fitted without smoking. In this model the dependent variable is diabetic risk score while the independent variable in the model are Age, Gender, Occupation Status , Hypertension, Family History, Cholesterol level, Exercise and obesity. The result of step- 2 provides that on the basis of $p$-value at $5 \%$ level of significance. The significant risk factors are Age, Cholesterol level Hypertension, Family History, Exercise and obesity, while the insignificant risk factors are gender and Occupation Status, at $5 \%$ level of significance.

Table 3 : Risk Factors in the Equation (step-1)

\begin{tabular}{|l|l|l|l|l|l|}
\hline Risk Factors & Coefficient & S.E. & Wald & df & $\mathbf{p}$ \\
\hline Age & 0.018 & 0.005 & 3.6 & 1 & 0.000 \\
\hline Gender & 0.115 & 0.152 & 0.577 & 1 & 0.448 \\
\hline $\begin{array}{l}\text { Occupation } \\
\text { Status }\end{array}$ & -0.110 & 0.159 & 0.478 & 1 & 0.489 \\
\hline $\begin{array}{l}\text { Cholesterol } \\
\text { Level }\end{array}$ & -0.534 & 0.135 & 15.71 & 1 & 0.000 \\
\hline Hypertension & 0.554 & 0.142 & 15.14 & 1 & 0.000 \\
\hline $\begin{array}{l}\text { Family } \\
\text { History }\end{array}$ & 0.270 & 0.133 & 4.121 & 1 & 0.042 \\
\hline Smoking & 0.111 & 0.179 & 0.386 & 1 & 0.534 \\
\hline Exercise & 0.325 & 0.147 & 4.899 & 1 & 0.027 \\
\hline Obesity & 0.418 & 0.166 & 6.349 & 1 & 0.012 \\
\hline Constant & -0.899 & 0.488 & 4.027 & 1 & 0.045 \\
\hline
\end{tabular}

In step-3 the relative risk factors are (Age, Gender, Cholesterol level, Hypertension, Family History, Exercise and obesity) while the dependent variable in the model is diabetic vs non-diabetic patient for diabetic $(\mathrm{y}=1)$. The table shows that the risk factors included in model are all significant except Gender , occupation status and smoking. The BLRM suggest that the risk factors Gender, Smoking and Occupation Status are insignificant on the basis of p-value at $5 \%$ level of significance while the factors which causing the diabetic are (Age, Cholesterol level, Hypertension, and Obesity) at 5\% level of significance because all 
the $\mathrm{p}$-values of the concern risk factors are less than $5 \%$ Level of significance but the exercise is insignificant at $5 \%$ level of significance. In step- 4 estimation terminated at iteration because parameter estimates change by less than 0.001 .

Table 4 : Risk Factors in the Equation (step-2)

\begin{tabular}{|l|l|l|l|l|l|}
\hline Risk Factors & Coefficient & S.E. & Wald & df & p \\
\hline Age & 0.018 & 0.005 & 3.6 & 1 & 0.000 \\
\hline Gender & 0.095 & 0.148 & 0.410 & 1 & 0.522 \\
\hline $\begin{array}{l}\text { Occupation } \\
\text { Status }\end{array}$ & -0.100 & 0.158 & 0.400 & 1 & 0.527 \\
\hline $\begin{array}{l}\text { Cholesterol } \\
\text { Level }\end{array}$ & -.537 & 0.135 & 5.892 & 1 & 0.000 \\
\hline Hypertension & 0.556 & 0.142 & 15.2 & 1 & 0.000 \\
\hline $\begin{array}{l}\text { Family } \\
\text { History }\end{array}$ & 0.268 & 0.133 & 4.060 & 1 & 0.04 \\
\hline Exercise & 0.318 & 0.147 & 0.472 & 1 & 0.030 \\
\hline Obesity & 0.417 & 0.166 & 6.349 & 1 & 0.012 \\
\hline Constant & -0.823 & 0.431 & 3.65 & 1 & 0.056 \\
\hline
\end{tabular}

The BLRM suggest that the risk factors Gender, Smoking and Occupation Status are insignificant on the basis of $\mathrm{p}$-value at $5 \%$ level of significance while the factors which causing the diabetic are (Age, Cholesterol level, Hypertension, and Obesity) at 5\% level of significance because all the $\mathrm{p}$-values of the concern risk factors are less than 5\% Level of significance but the exercise is insignificant at $5 \%$ level of significance. In step-4 estimation terminated at iteration because parameter estimates change by less than 0.001 .

Table 5 : Risk Factors in the Equation (step-3)

\begin{tabular}{|l|l|l|l|l|l|}
\hline Risk Factors & Coefficient & S.E. & Wald & df & p \\
\hline Age & 0.018 & 0.005 & 14.15 & 1 & 0.000 \\
\hline Gender & 0.127 & 0.139 & 0.831 & 1 & 0.362 \\
\hline $\begin{array}{l}\text { Cholesterol } \\
\text { Level }\end{array}$ & 0.536 & 0.135 & 15.88 & 1 & 0.000 \\
\hline Hypertension & 0.554 & 0.142 & 15.156 & 1 & 0.000 \\
\hline Family & 0.269 & 0.133 & 4.101 & 1 & 0.043 \\
\hline
\end{tabular}

\begin{tabular}{|l|l|l|l|l|l|}
\hline History & & & & & \\
\hline Exercise & 0.306 & 0.145 & 4.453 & 1 & 0.035 \\
\hline Obesity & 0.411 & 0.166 & 6.159 & 1 & 0.013 \\
\hline Constant & -0.92 & 0.400 & 5.324 & 1 & 0.021 \\
\hline
\end{tabular}

Table 6 : The Odds Ratios Results

\begin{tabular}{|l|l|ll|}
\hline Factors & Odds Ratio & $95 \%$ CI & \\
\hline age & 1.0177 & $(1.008$ & \\
& & $1.0273)$ & \\
& & $(0.4534$ &, \\
\hline Cholesterol Level & 0.5898 & $0.7671)$ & \\
& & $(1.3404$ &, \\
\hline Hypertension & 1.7681 & $2.3324)$ & \\
& & $(1.0199$ & \\
\hline Family History & 1.3220 & $1.7134)$ & \\
& & $(1.1127$ &, \\
\hline Obesity & 1.5360 & $2.1202)$ & \\
\hline
\end{tabular}

\subsection{Goodness of Fit Tests}

The Hosmer-Lemeshow statistic value $=.844$ means that it is not statistically significant which indicates that the observed and model forecast value have no difference and result of pvalue $=.884$ will indicate a better fit because .884 near to 1 .

Table 7 : Goodness of Fit Test

\begin{tabular}{|l|l|l|l|}
\hline Test & $\mathrm{df}$ & Chi Square & P-Value \\
\hline Deviance & 1014 & 1325.01 & 0.000 \\
\hline Pearson & 1014 & 1021.31 & 0.430 \\
\hline $\begin{array}{l}\text { Hosmer- } \\
\text { Lemeshow }\end{array}$ & $\mathbf{8}$ & 4.15 & 0.844 \\
\hline
\end{tabular}

\subsection{AIC Results}

Now to compare the results of P-values and AIC the next table explain AIC of the best fitted BLRM for Malakand Division Diabetic patients and Non diabetic patients. The table shows AIC (Akaike Information Criterion) of the various models to know the best fitted model from a set of models. 
Table 8 : AIC Results of Models

\begin{tabular}{|l|l|l|}
\hline Steps & Binary Logistic Regression Model & AIC value \\
\hline 1 & Age+G+OS+CRL+H+FH+S+E+O & 1343.39 \\
\hline 2 & Age+G+OS+H+CRL+FH+E+O & 1341.78 \\
\hline 3 & Age+ G+CRL+H+S+E+O+FH & 1340.18 \\
\hline 4 & Age+CRL+H+FH+O & 1339.01 \\
\hline
\end{tabular}

The above table 8 shows the AIC value results for various fitted binary logistic regression models. The best fitted binary logistic regression model for the District Malakand population is in step 4. The independent variables Age, Cholesterol (CRL), Hypertension(H), Family History $(\mathrm{FH})$ and Obesity $(\mathrm{O})$ are more serious risk factors for the Diabetic patients of Malakand Division population.

\section{VII.DISCUSSION}

The data have been taken from the four districts of Malakand Division. The total recorded diabetic and non-diabetic patients in the region are 1,021, a part of which 507 are diabetic patients and 514 are non-diabetic patients. The district wise recorded diabetic patients in which the highest number of patients found in District Swat which is about 335 patients in which diabetic patients are 175 and non-diabetic patients are 160. The second highest number of patients are in District Bunair which is 247 in which diabetic patients are 136 and non-diabetic patients are 111. Third total number of patients in District Lower Dir are 227 in which diabetic patients are 110 and nondiabetic patients are 117 while in District Malakand total number of patients are 212 in which 86 are diabetic patients and 126 are nondiabetic patients. The Binary Logistic Regression Model and AIC Technique is fitted first for Malakand Division and then fitted for concerned Districts of Malakand Division. The Binary Logistic Regression Model is fitted with independent risk factors in the model are Age, Gender, Occupation Status, Cholesterol Level,
Hypertension, Family History, Smoking, Exercise and obesity while the dependent variable in the model is diabetic risk score (Yes $=1 \mathrm{Vs}$ No=0). The Binary Logistic Regression Model is fitted for the whole data of Malakand Division. The result will be displayed stepwise with the help of Backward Elimination Method. In first step the significant risk factor in the model are Age, Hypertension, Family History, Exercise and obesity on the basis of $\mathrm{P}$ value at 5\% Level of Significance. In second step the significant risk factor for Malakand Division population on the basis of $\mathrm{P}$ value at $5 \%$ Level of Significance provide the same result only difference is that the model is fitted without risk factor Smoking while in third step the model is fitted without Smoking and Occupation Status, still the significance risk factor are Age, Cholesterol Level, Hypertension, Family History, Exercise and Obesity at 5\% Level of Significance. Now in final fifth step the Binary Logistic Regression Model is fitted without insignificant risk factor. The model suggests that the risk factors Age, Cholesterol Level, Hypertension, Family History and Obesity have serious effect on the diabetic patient, while AIC Technique also suggest the same result because its value is less than other fitted model for whole data of Malakand Division. The odd ratio with 95\% confidence interval shows that there is positive association among the risk factor Age, Hypertension, Family History, Exercise and Obesity with diabetes because there $\mathrm{OR}>1$ while Cholesterol Level have low number for diabetes because its OR. In the comparative studies of $\mathrm{P}$ values, AIC technique, Chi-square and Wald test. We conclude that the closes risk factors for causing diabetes in the region or initi64 ated by the AIC technique that reflect the best result in compression to $\mathrm{P}$ value because some risk factors are insignificant in $\mathrm{P}$ - value result but it is significant in the AIC fitted Models like the statistically significant risk factor for whole data of Malakand Division are Age, Cholesterol level, 
Hypertension, Family history and Obesity which are the major serious risk factors for diabetes as well as these factor are also statistical significant on the basis of Pvalue at $5 \%$ level of significance while the AIC technique show the same best fitted model as compare to other models for Malakand Division the result of chisquare test of association conclude that the risk factors age, cholesterol level, hypertension family history and obesity are associated with diabetes while Wald test result also indicate that the logistic coefficient of risk factors age, cholesterol level, hypertension, family history and obesity are significant as independent variables of diabetes. In district wise study of the risk factors age, gender, cholesterol level, hypertension, family history, occupation status, smoking, exercise and obesity.

\section{REFERENCES}

[1]. Aamir, A. H., Z. Ul-Haq, S. A. Mahar, F. M. Qureshi, I. Ahmad, A. Jawa, A. Sheikh, A. Raza, S. Fazid, Z. Jadoon, O. Ishtiaq, N. Safdar, H. Afridi, and A. H. Heald. 2019. Diabetes prevalence survey of pakistan (dps-pak): prevalence of type 2 diabetes mellitus and prediabetes using hbalc: a population-based survey from pakistan. BMJ open, 9(2):1-9. 2.

[2]. Adnan, M. and M. Aasim .2020. Prevalence of type 2 diabetes mellitus in adult population of pakistan: a metaanalysis of prospective crosssectional surveys. Annals of Global Health, 86(1): 1-8.

[3]. Ahmad, Z. and M. K. Pervaiz 2006. Risk factors and diabetes mellitus (statistical study of adults in lahore, pakistan). Journal of Statistics, 13(1): 4666.

[4]. Ahmed, H., I. Thaver, and I. Manzoor .2017. Risk factors associated with diabetes in periurban community, lahore pakistan. Pakistan journal of medical sciences, 33(6): 1381-1384.
[5]. Aisha Qadir, L. N. G. Y., Sumera Sohail and N. Iqbal. 2019. Prevalence of risk factors promoting diabetic neuropathy . Pakistan Journal of Neurological Sciences, 14: 16-23.

[6]. Alberti, K. G. M. M., R. H. Eckel, S. M. Grundy, P. Z. Zimmet, J. I. Cleeman, K. A. Donato, J.-C. Fruchart, W. P. T. James, C. M. Loria, and S. C. Smith. 2009. Harmonizing the metabolic syndrome. Circulation, 120(16): 1640- 1645.

[7]. Basit, A., A. Fawwad, H. Qureshi, and A. S. Shera. 2018. Prevalence of diabetes, pre-diabetes and associated risk factors: second national diabetes survey of pakistan (ndsp), 2016-2017. BMJ open, 8(8), e020961.

[8]. Chen, R., Y. Yang, F. Miao, Y. Cai, D. Lin, J. Zheng, and Y. Li. 2017. 3-year risk prediction of coronary heart disease in hypertension patients: A preliminary study. In 2017 39th Annual International Conference of the IEEE Engineering in Medicine and Biology Society (EMBC), IEEE.

[9]. Cox, D. R., D. V. Hinkley, and O. E. BarndorffNielsen 1996. Time Series Models: In econometrics, finance and other fields, volume 65, CRC Press.

[10].Devi, M. . N., A. alias Balamurugan, and M. R. Kris 2016. Developing a modified logistic regression model for diabetes mellitus and identifying the important factors of type ii $\mathrm{dm}$. Indian Journal Of Science And Technology, 9(4):1-8.

[11].Fink, J. T., E. M. Magnan, H. M. Johnson, L. M. Bednarz, G. O. Allen, R. T. Greenlee, D. M. Bolt, and M. A. Smith. 2018. Blood pressure control and other 67 quality of care metrics for patients with obesity and diabetes: A population-based cohort study. Le Jacq Ltd, 25(2): 391-399.

[12].Florez, J. C., J. Hirschhorn, and D. Altshuler. 2003. The inherited basis of diabetes mellitus: implications for the genetic analysis of complex traits. Annual review of genomics and human 
genetics, 4(1): 257-291. Haire-Joshu, D. and J. Thomas. 2005. Gambling with addiction: Dangerous beliefs about smoking and diabetes. Diabetes Voice, 50(I): 15-18.

[13].Hirschhorn, J. N. 2003. Genetic epidemiology of type 1 diabetes. Pediatric diabetes, 4(2): 87-100.

[14].Hosmer, D. W. and S. Lemeshow. 2000. Applied Logistic Regression, John Wiley \& Sons, Inc. Hosmer Jr, D. W., S. Lemeshow, and R. X. Sturdivant. 2013. Applied Logistic Regression, volume 398, John Wiley \& Sons.

[15].IDF. 2011. Ispad guideline for diabetes in childhood and adolescence. International diabetes federation, 131: 461-465.

[16].Islam, R. and O. Rahman. 2012. The risk factors of type 2 diabetic patients attending rajshahi diabetes association, rajshahi, bangladesh and its primary prevention. Food Public Health, 2:5-11.

[17].Ismail, B. and M. Anil. 2014. Regression methods for analyzing the risk factors for a life style disease among the young population of india. indian heart journal, 66(6):587-592.

[18].Kim, S. Y., J. L. England, J. A. Sharma, and T. Njoroge 2011. Gestational diabetes mellitus and risk of childhood overweight and obesity in offspring: a systematic review. Experimental diabetes research: 541308-541317.

[19].L'Heveder, R. and T. Nolan 2013. International diabetes federation. Diabetes research and clinical practice, 101(3): 349-351.

[20].Mohan, V., Z. Madan, R. Jha, R. Deepa, and R. Pradeepa. 2004. Diabetes- social and economic perspectives in the new millenium. International journal of diabetes in developing countries, 24(2):29-35.

[21].Montgomery, S. 2005. A very bad start: smoking, pregnancy and diabetes. DIABETES VOICE, 50(I):30-32.

[22].Mühlhauser, I., R. Bender, U. Bott, V. Jörgens, M. Grüsser, W. Wagener, H. Overmann, and M. Berger 1996. Cigarette smoking and progression of retinopathy and nephropathy in type 1 diabetes. Diabetic Medicine, 13(6):536-543.

[23].Okosun, I. S., R. S. Cooper, C. N. Rotimi, B. Osotimehin, and T. Forrester 1998. Association of waist circumference with risk of hypertension and type 2 diabetes in nigerians, jamaicans, and african-americans. Diabetes care, 21(11): 18361842.

[24].Robert and Jhon. 1972. Generalized linear models. Journal of the Royal Statistical Society: Series A (General), 135(3): 370-384.

[25].Rubens, M., A. Saxena, V. Ramamoorthy, R. Khera, J. Hong, E. Veledar, and K. Nasir. 2018. Trends in diabetes-related preventable hospitalizations in the us, 2005-2014. Diabetes Care, 41(5): e72-e73.

[26].Saeedi, P., I. Petersohn, P. Salpea, B. Malanda, S. Karuranga, N. Unwin, S. Colagiuri, L. Guariguata, A. A. Motala, K. Ogurtsova, J. E. Shaw, D. Bright, and R. Williams 2019. Global and regional diabetes prevalence estimates for 2019 and projections for 2030 and 2045: Results from the international diabetes federation diabetes atlas, 9th edition. Diabetes research and clinical practice, 157: 107843.

[27].Satman, I., B. Omer, Y. Tutuncu, S. Kalaca, S. Gedik, N. Dinccag, K. Karsidag, S. Genc, A. Telci, and B. Canbaz 2013. Twelve-year trends in the prevalence and risk factors of diabetes and prediabetes in turkish adults. European journal of epidemiology, 28(2): 169-180.

[28].Shera, A. S., A. Basit, A. Fawwad, R. Hakeem, M. Y. Ahmedani, M. Z. I. Hydrie, and I. A. Khwaja. 2010. Pakistan national diabetes survey: Prevalence of glucose intolerance and associated factors in the punjab province of pakistan. Primary care diabetes, 4(2): 79-83.

[29].Swade, T. F. and N. V. Emanuele. 1997. Alcohol \& diabetes. Comprehensive therapy, 23(2):135140. World Health Organization (WHO). 2011. Guidelines for the programmatic management of 
drugresistant tuberculosis-2011 update. WHO/HTM/TB/2011.6,

[30]. World Health Organization (WHO) 2013. The european health report 2012: Charting the way to wellbeing. executive summary:163-172.

[31].Willi, C., P. Bodenmann, W. A. Ghali, P. D. Faris, and J. Cornuz (2007). Active smoking and the risk of type 2 diabetes: a systematic review and metaanalysis. Jama, 298(22):2654-2664.

[32].Zafar, J., F. Bhatti, N. Akhtar, U. Rasheed, R. Bashir, S. Humayun, A. Waheed, F. Younus, and M. Nazar 2011. Prevalence and risk factors for diabetes mellitus in a selected urban population of a city in punjab. JPMAJournal of the Pakistan Medical Association, 61(1):40-47.

\section{Cite this article as :}

Zahid Iqbal, Qaiser, "Regression Analysis for Analyzing Life Style Risk Factor of Diabetes in Pakistan", International Journal of Scientific Research in Science and Technology (IJSRST), Online ISSN : 2395-602X, Print ISSN : 2395-6011, Volume 8 Issue 1, pp. 94-103, January-February 2021. Available at doi : https://doi.org/10.32628/IJSRST207551 Journal URL : http://ijsrst.com/IJSRST207551 